\title{
Percutaneous Salivary Gland Ablation using Ethanol in a Rat Model
}

\author{
Emma Burch $^{1}$, Lacey Lubeley ${ }^{1}$, James Murakami ${ }^{1}$ \\ ${ }^{1}$ Department of Radiology, Nationwide Children's Hospital, Columbus, Ohio, USA.
}

\author{
Corresponding Author: \\ James Murakami \\ Radiology Department, Nationwide Children's Hospital \\ 700 Children's Drive, Columbus, OH 43205 \\ USA \\ Phone: +1 6147222289 \\ Fax: +16147222332 \\ E-mail: James.Murakami@nationwidechildrens.org
}

\begin{abstract}
Objectives: Sialorrhea is a common health and psychosocial problem for children with neuromuscular dysfunction secondary to a variety of disorders such as cerebral palsy. Current accepted treatments include the injection of botulinum toxin into the submandibular glands for temporary symptom relief. The purpose of this study is to demonstrate the feasibility of percutaneous ethanol injection for longer lasting salivary gland ablation in an animal model.

Material and Methods: Twenty rats were used in this study. In each rat, $98 \%$ ethanol was injected into the right submandibular gland under ultrasound guidance. No intervention was performed on the left gland, which served as the control. Ten rats were sacrificed and glands evaluated at three weeks, with the remaining 10 rats sacrificed and evaluated at three months. Unpaired, 1-tailed T-tests were used to analyse the data.

Results: Ethanol injections induced a significant and sustained reduction in salivary gland size. Treated glands were $41 \%$ smaller by mass than untreated controls in the 10 rats sacrificed at three weeks $(\mathrm{P}<0.001)$. Treated glands were $43 \%$ smaller by mass than untreated controls in the 10 rats sacrificed at three months $(\mathrm{P}<0.001)$. Qualitative histologic analysis demonstrated extensive parenchymal damage, inflammation, and fibrosis at both three week and three month time points.

Conclusions: Using a rat model, we demonstrated dramatic and sustained submandibular gland damage after percutaneous injection of ethanol.
\end{abstract}

Keywords: ethanol; injections; rat; sialorrhea; submandibular gland.

Accepted for publication: 29 December 2017

To cite this article:

Burch E, Lubeley L, Murakami J.

Percutaneous Salivary Gland Ablation using Ethanol in a Rat Model

J Oral Maxillofac Res 2017;8(4):e3

URL: http://www.ejomr.org/JOMR/archives/2017/4/e3/v8n4e3.pdf

doi: $10.5037 /$ jomr.2017.8403 


\section{INTRODUCTION}

Sialorrhea, commonly known as drooling, occurs when saliva extends beyond the lip margin. Sialorrhea is a normal physiologic event in babies prior to establishing salivary continence. It is considered pathologic if it persists beyond four years of age $[\underline{1,2}]$. For the remainder of this paper, sialorrhea will be considered the pathological type. Sialorrhea in children is found in a variety of neurological disorders, with Cerebral Palsy being the most common. This has been attributed primarily to impaired neuromuscular function which results in the inability to swallow saliva secondary to uncoordinated tongue and oral movements [1].

Sialorrhea in children has negative health and social consequences including social isolation, perioral maceration, skin infections, dehydration, and aspiration secondary to pooling of excess saliva in the oral cavity [1-5]. Current management strategies include oral motor and pharmacologic therapies [4], botulinum toxin injectable therapy [ㅁ] , and surgical interventions [6]. In addition, one of the strategies employed at our institution in sialorrhea management is percutaneous ethanol ablation of salivary glands. The objective of this study is to validate this approach using a rat model. We hypothesize percutaneous ethanol injection into the submandibular glands will provide long lasting salivary gland ablation in an animal model. To our knowledge, this is the first study of its kind employing ethanol in a rat model.

Mammals have three major salivary glands. In order of decreasing size they are the parotid, submandibular (SMG), and sublingual (SLG). Generally speaking, the volume of saliva produced by each gland is proportional to its size. However, in the absence of salivary stimuli, the SMG is responsible for the majority of saliva production [1]. For this reason, we elected to target the SMG in this study.

\section{MATERIAL AND METHODS}

After obtaining approval from our Institutional Animal Care and Use Committee, a controlled animal trial was conducted (No.: AR09-00052). Twenty healthy, male, retired breeder, Sprague Dawley rats weighing between $454 \mathrm{~g}$ and $583 \mathrm{~g}$ (Harlan/Envigo, Indianapolis, IN, USA) were obtained. Adult rats were used to minimize physiologic growth of salivary glands, which would be expected in adolescent rats over the course of this experiment. 6

All rats $(n=20)$ underwent the same treatment procedure on the same day. At the time of treatment, the rats were anaesthetized with isoflurane (1 to $4 \%$ inhaled; Baxter International, Deerfield, IL, USA). The rat SMGs were superficially located on the ventral aspect of the neck. Under ultrasound guidance, a 30 gauge needle was advanced medially to laterally into the right SMG. 98\% ethanol (Acorn, Inc., Lake Forest, IL, USA) was injected while withdrawing the needle (Figure 1). Ethanol treatment volume averaged $0.39 \mathrm{ml}$ (range 0.2 to $0.5 \mathrm{ml}$ ). Rats were given $0.1 \mathrm{ml}$ Buprenorphine (Reckitt Benkiser, Slough, England, UK) for analgesia and allowed to recover. The left SMG of each rat was left untouched to serve as an internal control.

Rats were monitored weekly for signs of swelling, weight loss, and distress until sacrifice using carbon dioxide (43 to 47 liters/minute inhaled; Praxair, Inc., Danbury, CT, USA). Ten rats were sacrificed after three weeks and all SMGs were harvested and evaluated. After three months, the remaining ten rats

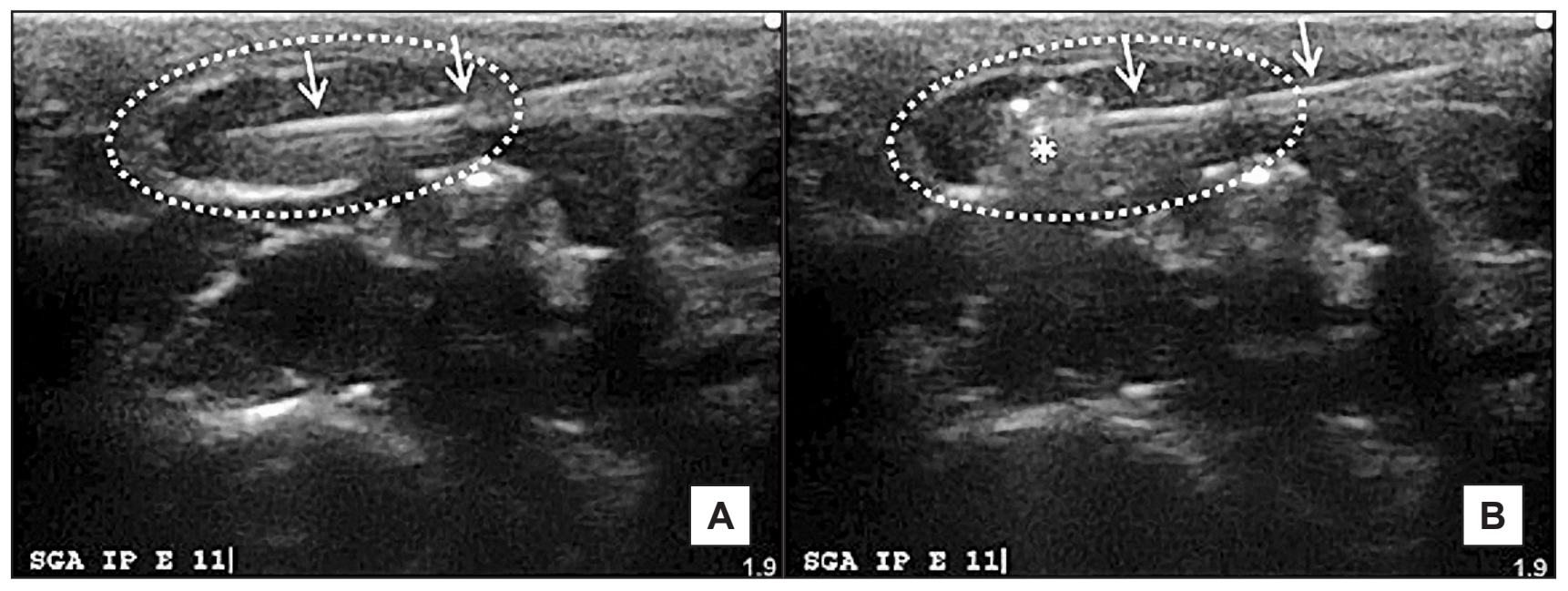

Figure 1. Ultrasound images demonstrate (A) the advancement of the needle, indicated by double white arrows, and (B) the deposition of $98 \%$ ethanol, marked with $(*)$, within the parenchyma of the right SMG, outlined with a dotted line. 
underwent sacrifice and SMG harvest for evaluation. Care was taken to remove surrounding non-glandular tissue prior to obtaining measurements. To aide with clarity, we shall here after refer to the 10 rats sacrificed at 3 weeks as Group A and the 10 rats sacrificed at 3 months as Group B.

The SLG of a rat is intimately adherent to the SMG. Histologically, the SLG appears much different than the SMG. The SLG is made up of primarily mucinous glands with the SMG being predominantly serous. Grossly, it is very difficult to distinguish the much smaller SLG from the SMG. To avoid damage to the SMG, the SLG was left intact and included in all measurements. The small size of the SLGs made a relatively minor contribution to measurements obtained, and they are included in both the treated and control glands.

\section{Measurements}

The mass was recorded at the time of excision for treated and untreated control glands in both groups. The mass was recorded in grams using a clean balance capable of measuring to one-thousandth of a gram.

\section{Histology}

All SMGs were fixed in $10 \%$ formalin solution Sections were stained with hematoxylin eosin for general morphology. We qualitatively examined the slides of all treated and control glands for signs of damage. As our laboratory was not equipped to perform a more quantitative histologic analysis, and determining the exact mechanism of ethanol ablation is beyond the scope of this paper, we did not pursue further histologic evaluation.

\section{Statistical analysis}

Calculations and statistical analyses were performed in Microsoft Excel 2010. Unpaired, 1-tailed t-tests were run to compare treated glands to controls in Group A and B. An additional unpaired, 1-tailed t-test was run to compare treated glands from Group A to those from Group B. P-value $<0.001$ was considered statistically significant.

\section{RESULTS}

In Group A, treated glands were $41 \%$ smaller, on average, than their untreated counterpart's by mass. The effect of the ethanol treatment was the same in Group B, with treated glands being 43\% smaller by mass than their respective controls. There was no statistically significant difference between the mass of treated glands between Group A and $\mathrm{B}(\mathrm{P}=0.18)$. Box and whisker plots (Figure 2)

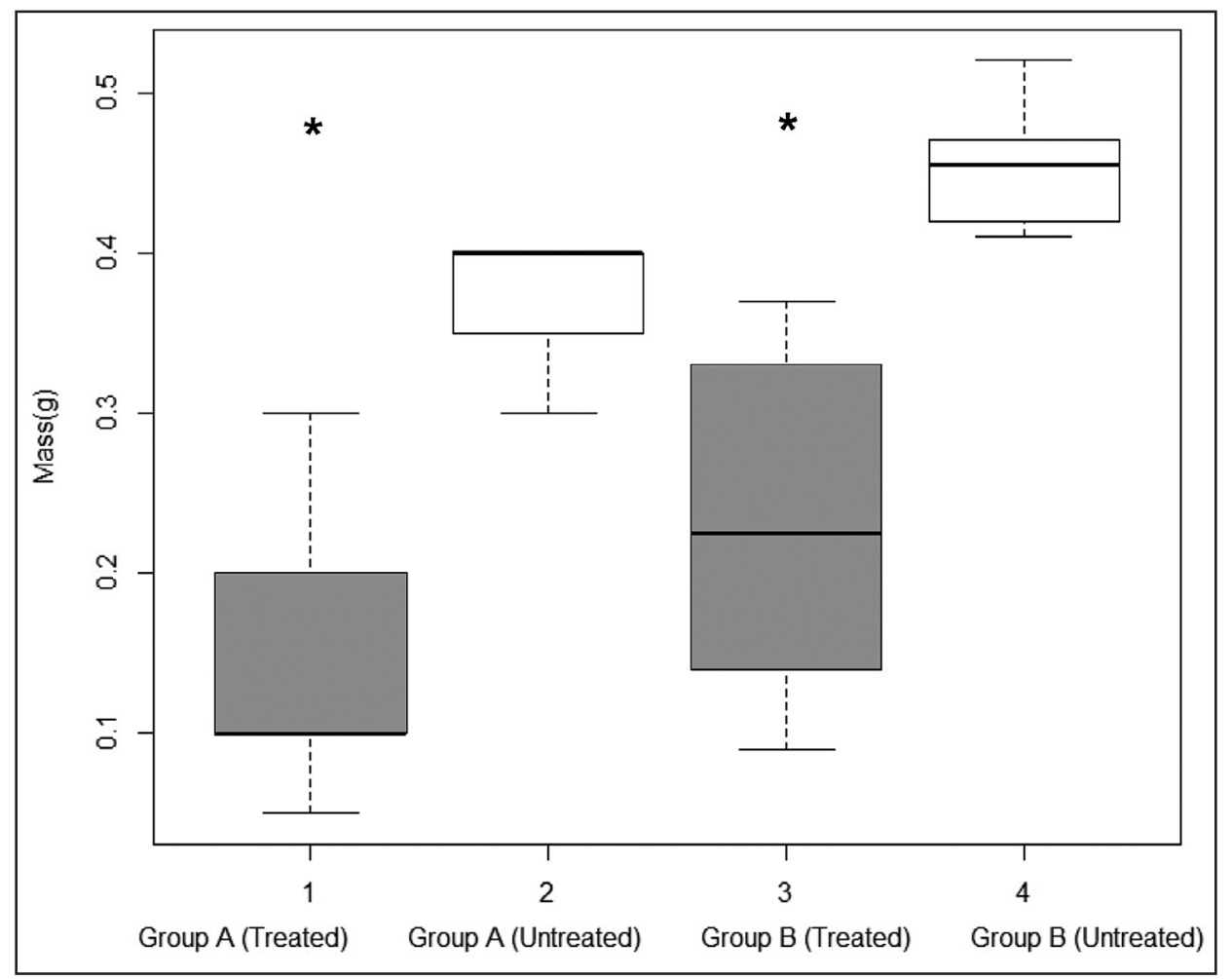

Figure 2. Gland measurements obtained for mass. Comparisons between untreated controls (white) and treated glands (grey) can be seen in Groups A and B. $\left(^{*}\right)$ indicates statistically significant difference $(\mathrm{P}<0.001)$. 
demonstrate the difference between treated and control glands for both groups.

The majority of the rats experienced noticeable swelling at the site of injection which resolved within a week. However, this did not appear to interfere with their ability to eat or drink as rats did not lose any significant amount of weight after the procedure. In fact, the rats had a $4 \%$ increase in weight on average when comparing their sacrifice weight to their procedure weights.

At the time of gland harvest, treated glands were notably smaller than their untreated counterparts (Figure 3). Treated glands also tended to be surrounded by more fibrous tissue and yellow, chalky deposits of fat necrosis. Yellow deposits were also noted on the glands themselves.

In addition to decreased size, qualitative histological signs of parenchymal damage were evident even at low magnification (Figure 4). Treated glands showed subjectively weaker staining of acini and ducts, ductal proliferation, areas of denucleated acini, increased connective tissue, and decreased acinar density. Lymphocytic infiltrates were also evident throughout the treated glands in Group A.

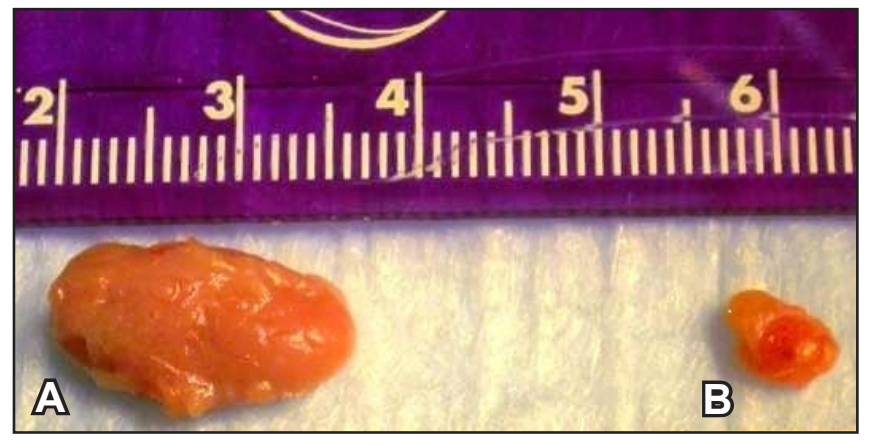

Figure 3. Representative image of an (A) untreated and (B) ethanol treated SMG from the same rat from Group B.

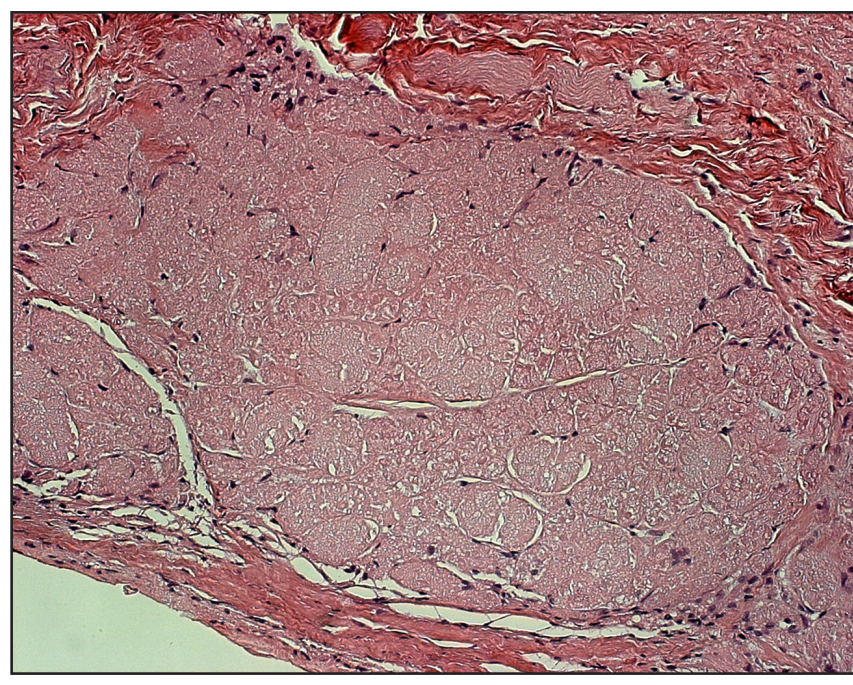

Figure 5. A representative treated gland from Group B demonstrates an area of devitalized glandular tissue with retained cytoarchitecture. Hematoxylin and eosin stain, original magnification x20.

Extensive cell death continued to be evident in Group B. There was decreased glandular tissue within the treated glands. In the existing submandibular tissue, there were large areas where cytoarchitecture was preserved but there were no viable cells as demonstrated by the lack of nuclear material (Figure 5).

\section{DISCUSSION}

Sialorrhea is a common paediatric condition that has a negative impact on the health and well-being of those affected and those who care for them. At our institution, it is a goal to offer these families simple and effective treatment options that will improve not only the health of these children, but also the quality of life of their families.

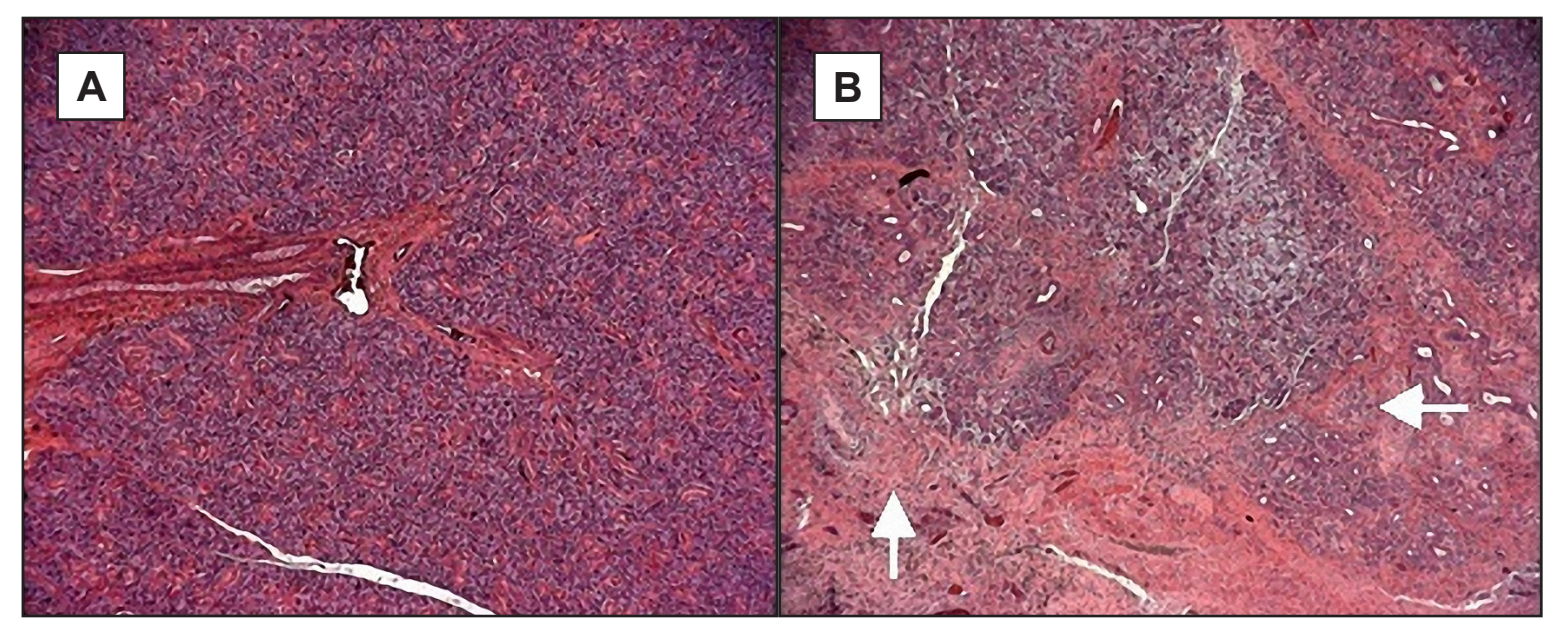

Figure 4. Representative images comparing gland parenchyma of untreated control (A) and treated gland (B) from the same rat from Group A. Treated glands demonstrate noticeably decreased acinar density and increased connective tissue. Arrows identify areas of fibroconnective tissue which has replaced normal glandular tissue. Hematoxylin and eosin stain, original magnification x5. 
Rats have been used as an animal model for sialorrhea management techniques for decades [79]. The anatomy of the rat salivary structures is well documented [10], and correlation between animal interventions and clinical outcomes has been established [욤1-13]. In our study, we demonstrated that percutaneous ethanol injection into the SMG resulted in a significant decrease in gland size. Through our qualitative histologic review of the glands, extensive cellular damage and increase in connective tissue was seen in both groups. Our laboratory was not equipped to quantify salivary production in the way utilized by previous investigators [14], or perform a semi-qualitative and morphometric histological analysis [15]. However, the results of those researchers allow us to be confident in using gland size and general appearance as an acceptable proxy for salivary gland function [16].

We used ethanol as the ablative agent because it is both readily available and inexpensive. Ethanol is a very caustic agent, and is used as an effective sclerosant in many clinical scenarios [17-20]. Ethanol destroys cells via dehydration, protein denaturation, coagulation, necrosis, small vessel thrombosis, haemorrhagic infarction, and reactive fibrosis [17]. After the initial inflammatory insult, damaged cells are replaced with connective tissue preventing regrowth [20]. This lasting tissue destruction is what makes ethanol an attractive treatment option for salivary gland ablation.

Percutaneous injection of ethanol does come with some risk of adverse events $[\underline{18}, \underline{19}]$. One rat in this study develped a skin ulcer at the site of the injection three weeks after treatment. The wound was fully healed at 8 weeks post treatment. At the time of the sacrifice, the treated gland was found to be almost identical in size to its control. We believe the ethanol was primarily deposited into the tissues surrounding the SMG at the time of treatment instead of within the gland parenchyma. The glands of this rat were not included in data analysis. Although we took care to perform the ethanol injection under constant ultrasound guidance, there is still a risk of non-target tissue injury. The affected rat was one of the earlier animals in the study, whose injury likely reflects our developing experience with this technique.

Botulinum toxin is generally considered to be the first line injectable agent for sialorrhea management $[1,6]$ has and been shown to be effective in numerous animal [7-9] and human studies [6, 11-13]. Botulinum toxin works by temporarily preventing the release of acetylcholine $(\mathrm{ACh})$ from presynaptic vesicles, thus disrupting the effective innervation of the salivary gland. Glandular dysfunction occurring secondary to interruption of $\mathrm{ACh}$ has been reported [5]. As with the chemical blockade, this dysfunction is temporary $[\underline{6}, 7]$. A major advantage of botulinum toxin is that there are few side effects, one of which being transitory dysphagia [5]. A drawback of this approach is that botulinum toxin therapy for sialorrhea in the paediatric population requires sedation or anaesthesia. Due to the impermanent nature of botulinum toxin, multiple treatments will require repeated anaesthesia, with all its associated risks. The use of a longer acting agent such as ethanol circumvents this need for repeated sedation in the paediatric population.

This study was limited by the absence of salivary flow rate measurements and a quantitative histologic analysis. Further studies would help to solidify the relationship between histopathology, glandular size, and salivary flow production. The ultimate goal of ethanol ablation of salivary glands is to improve the quality of life of children affected with sialorrhea and their caretakers. Patient and family perception of efficacy after percutaneous ethanol ablation would be an area to study further.

\section{CONCLUSIONS}

In our animal model, ethanol injection proved to be an effective technique for long term ablation of salivary glands. It's effectiveness in rats warrants further studies as a potentially more permanent treatment of sialorrhea in children.

\section{ACKNOWLEDGMENTS AND DISCLOSURE STATEMENTS}

The authors have no conflicts of interest to disclose. No external funding, apart from the support of the authors' institution, was available for this study. The box and whisker plot was constructed by Mark G. Burch, Masters of Statistics, College of Public Health, The Ohio State University. Dr. W. E. Shiels II served as the Primary Investigator for most of the life of this research study. He was integral in developing the experimental design and acquiring data. Unfortunately, he passed away prior to the writing of this manuscript. 


\section{REFERENCES}

1. Lakraj AA, Moghimi N, Jabbari B. Sialorrhea: anatomy, pathophysiology and treatment with emphasis on the role of botulinum toxins. Toxins (Basel). 2013 May 21;5(5):1010-31. [Medline: 23698357] [PMC free article: $\underline{3709276]}$ [doi: $10.3390 /$ toxins5051010]

2. Reid SM, McCutcheon J, Reddihough DS, Johnson H. Prevalence and predictors of drooling in 7- to 14-year-old children with cerebral palsy: a population study. Dev Med Child Neurol. 2012 Nov;54(11):1032-6. [Medline: 22881219] [doi: 10.1111/j.1469-8749.2012.04382.x]

3. Leung AK, Kao CP. Drooling in children. Paediatr Child Health. 1999 Sep;4(6):406-11. [Medline: 20212951] [PMC free article: 2827743 ] [doi: $10.1093 / \mathrm{pch} / 4.6 .406$ ]

4. Bailey CM. Management of the drooling child. Clin Otolaryngol Allied Sci. 1988 Oct;13(5):319-22. [Medline: 3072130] [doi: 10.1111/j.1365-2273.1988.tb00759.x]

5. Cardona I, Saint-Martin C, Daniel SJ. Effect of recurrent onabotulinum toxin A injection into the salivary glands: An ultrasound measurement. Laryngoscope. 2015 Oct;125(10):E328-32. [Medline: 26198624] [doi: 10.1002/lary.25222]

6. Formeister EJ, Dahl JP, Rose AS. Surgical management of chronic sialorrhea in pediatric patients: 10-year experience from one tertiary care institution. Int J Pediatr Otorhinolaryngol. 2014 Aug;78(8):1387-92. [Medline: 24974144] [doi: 10.1016/j.ijporl.2014.06.005]

7. Ellies M, Laskawi R, Götz W, Arglebe C, Tormählen G. Immunohistochemical and morphometric investigations of the influence of botulinum toxin on the submandibular gland of the rat. Eur Arch Otorhinolaryngol. 1999;256(3):148-52. [Medline: 10234485$]$

8. Teymoortash A, Sommer F, Mandic R, Schulz S, Bette M, Aumüller G, Werner JA. Intraglandular application of botulinum toxin leads to structural and functional changes in rat acinar cells. Br J Pharmacol. 2007 Sep;152(1):161-7. [Medline: 17618309] [PMC free article: 1978275] [doi: 10.1038/sj.bjp.0707375]

9. Coskun BU, Savk H, Cicek ED, Basak T, Basak M, Dadas B. Histopathological and radiological investigations of the influence of botulinum toxin on the submandibular gland of the rat. Eur Arch Otorhinolaryngol. 2007 Jul;264(7):783-7. [Medline: 17285331]

10. Amano O, Mizobe K, Bando Y, Sakiyama K. Anatomy and histology of rodent and human major salivary glands: -overview of the Japan salivary gland society-sponsored workshop-. Acta Histochem Cytochem. 2012 Oct 31;45(5): 241-50. [Medline: 23209333] [doi: 10.1267/ahc.12013]

11. Lipp A, Trottenberg T, Schink T, Kupsch A, Arnold G. A randomized trial of botulinum toxin A for treatment of drooling. Neurology. 2003 Nov 11;61(9):1279-81. [Medline: 14610139] [doi: 10.1212/WNL.61.9.1279]

12. Jongerius PH, Rotteveel JJ, van Limbeek J, Gabreëls FJ, van Hulst K, van den Hoogen FJ. Botulinum toxin effect on salivary flow rate in children with cerebral palsy. Neurology. 2004 Oct 26;63(8):1371-5. [Medline: 15505151] [doi: 10.1212/01.WNL.0000142040.57474.A6]

13. Bothwell JE, Clarke K, Dooley JM, Gordon KE, Anderson R, Wood EP, Camfield CS, Camfield PR. Botulinum toxin A as a treatment for excessive drooling in children. Pediatr Neurol. 2002 Jul;27(1):18-22. [Medline: 12160968] [doi: 10.1016/S0887-8994(02)00381-8]

14. Correia PN, Carpenter GH, Osailan SM, Paterson KL, Proctor GB. Acute salivary gland hypofunction in the duct ligation model in the absence of inflammation. Oral Dis. 2008 Sep;14(6):520-8. [Medline: 18221457] [PMC free article: 2592348] [doi: 10.1111/j.1601-0825.2007.01413.x]

15. Abbas F, Farid R, Nada I, El-Sharnouby M. Evaluation of ethanolamine oleate sclerotherapy on the submandibular glands of canines as a potential therapy for sialorrhea. Int J Pediatr Otorhinolaryngol. 2013 Mar;77(3):351-5. [Medline: 23246419] [doi: 10.1016/i.ijporl.2012.11.024]

16. Osailan SM, Proctor GB, Carpenter GH, Paterson KL, McGurk M. Recovery of rat submandibular salivary gland function following removal of obstruction: a sialometrical and sialochemical study. Int J Exp Pathol. 2006 Dec;87(6):411-23. [Medline: 17222209] [doi: 10.1111/j.1365-2613.2006.00500.x]

17. Lee DK, Seo JW, Park HS, Kang MK, Jang AL, Lee JH, Hong JC. Efficacy of ethanol ablation for thyroglossal duct cyst. Ann Otol Rhinol Laryngol. 2015 Jan;124(1):62-7. [Medline: 25048959] [doi: 10.1177/0003489414542845]

18. Kim B, Kim K, Jeon P, Kim S, Kim H, Byun H, Kim D, Kim Y. Long-term results of ethanol sclerotherapy with or without adjunctive surgery for head and neck arteriovenous malformations. Neuroradiology. 2015 Apr;57(4):377-86. [Medline: 25563632] [doi: 10.1007/s00234-014-1483-3]

19. Benzimra J, Ronot M, Fuks D, Abdel-Rehim M, Sibert A, Farges O, Vilgrain V. Hepatic cysts treated with percutaneous ethanol sclerotherapy: time to extend the indications to haemorrhagic cysts and polycystic liver disease. Eur Radiol. 2014 May;24(5):1030-8. [Medline: 24563160] [doi: 10.1007/s00330-014-3117-x]

20. Weismüller P, Mayer U, Richter P, Heieck F, Kochs M, Hombach V. Chemical ablation by subendocardial injection of ethanol via catheter--preliminary results in the pig heart. Eur Heart J. 1991 Nov;12(11):1234-9. [Medline: 1782955] [doi: 10.1093/eurheartj/12.11.1234] 


\section{To cite this article:}

Burch E, Lubeley L, Murakami J.

Percutaneous Salivary Gland Ablation using Ethanol in a Rat Model

J Oral Maxillofac Res 2017;8(4):e3

URL: http://www.ejomr.org/JOMR/archives/2017/4/e3/v8n4e3.pdf

doi: $\underline{10.5037 / \text { jomr.2017.8403 }}$

Copyright @ Burch E, Lubeley L, Murakami J. Published in the JOURNAL OF ORAL \& MAXILLOFACIAL RESEARCH (http://www.ejomr.org), 31 December 2017.

This is an open-access article, first published in the JOURNAL OF ORAL \& MAXILLOFACIAL RESEARCH, distributed under the terms of the Creative Commons Attribution-Noncommercial-No Derivative Works 3.0 Unported License, which permits unrestricted non-commercial use, distribution, and reproduction in any medium, provided the original work and is properly cited. The copyright, license information and link to the original publication on (http://www.ejomr.org) must be included. 